\title{
Manipulation in Political Discourse of Mass Media
}

\author{
Kuralay Kenzhekanova
}

\author{
Magulsim Zhanabekova
}

Tolkyn Konyrbekova

Al-Farabi Kazakh National University, al-Farabi ave., 71, Almaty, 050038, Kazakhstan

\section{Doi:10.5901/mjss.2015.v6n4s1p325}

\section{Abstract}

The article discusses the main means of verbal persuasion used in political discourse, and their functions in the text. The concept of manipulation is defined from various perspectives and features peculiar to the political discourse of mass media are investigated. The political discourse is characterized by a combination of different tools of speech manipulation which found reflection in political discourse of mass media. And these reflections are given at different levels including phonographic, grammatical, lexical and lexical-pragmatic. The political discourse is characterized by manipulative feature for the purpose of conducting propaganda and ideological conflict which is done with the help of various linguistic units and methods such as alliteration, rhyme, rhythmization, nominalization, converse terms, neologisms, periphrases, deictic units, euphemisms, dysphemisms, sophisticated lexis, barbarisms, elliptic language and inversion. Political discourse of mass media has a huge impact on formulation of public opinion which is done with the help of the above-mentioned tools of speech manipulation.

Keywords: discourse, political discourse, mass media, mass influence, communication, addressee and addresser, phonographic level, grammatical level, lexical level and lexical-pragmatic level.

\section{Introduction}

"Probably, the language began to be used for the purpose of influence and manipulation since its moment of origin. And our ancient ancestor who guessed to use the word as an influence tool, but not as a cudgel, was, undoubtedly, one of the first manipulators" (Issers, 1996).

The tradition of studying manipulation goes back to works of psychologists, sociologists, political scientists. All these scientists estimate manipulation mainly as "impact on the person with the purpose to induce him to make something (to give information, to make an act, to change the behavior) unconsciously or contrary to his own desire, opinion and intention" (Troshina, 1990). Influence within institutional communication is carried out by means of agitation, propaganda, demagogy, belief, suggestion, persuasion and "public relations" (PR). Speech influence (SI) as a field of research studies processes of speech regulation of activity of one person or group of people. From the middle of the last century various aspects of this phenomenon were studied at audience which made it possible to talk about the formation of a new scientific discipline.

According to Teun A. Van Dijk, "as socially, manipulation is defined as illegitimate domination confirming social inequality. Cognitively, manipulation as mind control involves the interference with processes of understanding, the formation of biased mental models and social representations such as knowledge and ideologies. Discursively, manipulation generally involves the usual forms and formats of ideological discourse, such as emphasizing Our good things, and emphasizing Their bad things" (Dijk, 2006). Whereas speech manipulation (SM) is understood as "a type of language influence used for the hidden introduction of purpose, desire, intention, relations or attitudes which don't coincide with those available for the addressee into his mentality" (Veretenkina, 1999). In other words, when the hidden opportunities of language are used by the addressee of the utterance in order to impose a certain notion of reality to the addressee, to create the necessary attitude towards it, to cause emotional reaction necessary for addressee, we are talking about manipulation of speech.

\section{Literature Review}

The tool of speech manipulation (TSM) in its broad sense is any verbal sign which in a certain context and meaning can 
have necessary impact on the addressee. The person is tend to use the word for impact on the interlocutor - consciously or not. In case of conscious use of language it is possible to tell about speech manipulation in its true meaning, as this action, first of all, is purposeful. "Each language element is very difficult and sensitive tool on which plays the one who uses language. Thus, the perception and understanding created at the recipient depend on how the addresser uses this sensitive tool " (Blakar, 1987).

Various phonographic, lexical means, morphological categories, syntactic designs, text categories are used generally in interaction as a tool of speech manipulation. In this research the following levels of speech manipulation are highlighted: phonographic, lexical, and grammatical.

1. At the phonographic level speech manipulation is carried out by means of special sound and graphic registration of the message. Use of phonetic means - a prerogative of oral speech: both intonation, and a timbre, both allocation by voice, and pauses are applied. In a political discourse of mass media phonetic instruments of speech manipulation are widely used in oral types of a discourse. But in our study the materials are texts of printing editions, therefore tools of written language, phonographic ones are of great interest.

Some TSM of phonographic level is equally present both in oral and written language: alliteration, rhyme and rhythmization. These means which are urged to transfer features of a sound cover of the text are quite seldom. So, the following heading is an example of alliteration and a rhythmization: Re-win, re-run, re-up, USA, March 23, 2007. Parallel construction with prefix re-plus monosyllabic roots is used by the author. Thus, the special rhythm and dynamics are created which set the vigorous tone for all subsequent text, as well as in case of application in the following heading of a rhyme and rhythmization: Money talk, as you walk, Washington Post, February 24, 2007.

Other tools of speech manipulation at the phonographic level have no analogues in written language. However some of such means (intonation, register of a voice, tempo of speech and a pause) can be compensated by using graphic means: punctuation, meta-graphic means (underlining, font selection, capital letters).

Means of graphics cannot only be "transcription" of oral speech, but also the self-sufficient means of speech influence that provoke a certain utterance of written speech by the reader and it can also be markers of other tools of speech manipulation.

2. Lexical means of speech manipulation constitute the most extensive and frequently used area of tools of speech manipulation. Being the most extensive class, tools of speech manipulation at the lexical level allow systematization on the basis of their sign properties - semantics, syntactics and pragmatics. Respectively, depending on what aspect of a lexical unit as linguistic sign is involved in realization of manipulation, it is possible to divide lexical TSM into three groups: lexical-semantic, lexical-syntactic and lexical-pragmatic.

Nominalization is one of lexical-semantic tools; it is a transformation of the motivating construction from a verb into a verbal noun. Nominalization is a means of a depersonalization of action which is widespread in a political discourse. A semantic result of replacement of personal forms of verbs with derivative nouns is disappearance of the subject and agent of what about is told. For example: It isn't and secret that Arab immigrants suffer insult and abuse, Chicago Tribune, February 15, 2007.

Here usage of nouns insult and abuse (no corresponding verbs of action) allows the author to hold back the subject of an action.

Metaphor and a metonymy are widely popular in a political discourse of mass media. The war of words continues, New York Post, May 14, 2008. Nuclear weapons are all over, in friendly and unfriendly hands, New York Post, April 14, 2006. The seme of battle and large-scale use of means which are peculiar to war in its primary meaning are used in order to name informative fight of opponents.

Converse terms belong to the lexical-semantic group of TSM. For example, in the following passages results of governor's elections are described from the different points of view - a victory or a failure. A former Bush administration official ... ousted Indiana's sitting governor on Tuesday, USA, October 22, 2006. .. Republican Bob Brown was disgracefully beat by a ... political newcomer Democrat Brian Schweitzer, USA, October 22, 2006.

In the first passage converse term to oust is used which means "to force someone out of a position of power, especially so that you can take their place (Longman Dictionary of Contemporary English, 1995)". Thus, in this case the situation is shown from the point of view of the winner. In the second statement to be beat stands for "to be won" (to beat - "to win", to get the most points, votes etc in a game, race, or competition (Longman Dictionary of Contemporary English, 1995). Here events are presented from the position of the lost.

"Amoeba words" are so-called "transparent" words which aren't connected with a context of real life. They can be used practically in any context as they aren't connected with real subjects and phenomena (Kara-Murza, 2003). A distinctive feature of such words is extremely wide semantics in the context of a political discourse of mass media. They designate the abstract concept which doesn't have the concrete contents. "Brilliant universality" is a technique identical to 
"amoeba words", it is also called as "brilliant uncertainty" which is "a set of harmonious words which cause the benevolent relation of audience, but have no accurate certain content" (Vlasov, 1976).

E.g. Repeated suggestions by the White House and friendly commentators that the news media's selective displays of terrorist attacks in Iraq are warping American public opinion are belied by the U.S. State Department's own recent Country Report on Human Rights Practices for Iraq, Washington Post, March 23, 2006. "American public opinion" has no concrete content and isn't connected with real object; it is estimated abstract concept causing favorable effect. Such expressions are often used in a political discourse of mass media and directed on the description of scientifically supported opinion of residents of the country.

The group of lexical TSM includes neologisms which are defined as "invasion into language for the purpose of programming" by S.G. Kara-Murza (Kara-Murza, 2003). The effect of such lexical units depends on several factors: they give more exact meaning or on the contrary, mask it, coming nearer to amoeba words or terms, but anyway, they always rivet attention of the reader.

The United States has made clear its opposition to Lebanon's Hezbollethargy, and has crystallized its support for Israel's anti-Hezbollah campaign, Washington Post, July 13, 2007. In this example the use of neologism Hezbollethargy expresses criticism of the author to the Lebanese authorities who ignore terrorist activity of Hezbollah group.

Obamacare - a term of derogation for Barack Obama's Patient Protection and Affordable Care Act., which was proposed by the democratic leadership and became law in March 2010 (Dickson, 2013).

The changed (deformed) precedent phenomena are often used in a political discourse as TSM. The sources of such speech stereotypes can be the most different patterns: names of sensational movies, wide-spread songs, fragments of commercials, famous statements of public figures and politicians and so forth. Aphorisms and paraphrased proverbs are often used.

E.g. Cheney pans Kerry's goose, USA, October 23, 2005.

The title of the article in the given example uses the phraseological unit to pan sb's goose which means "to get someone into serious trouble (Longman Dictionary of Contemporary English, 1995), but at the same time it correlates with a real goose which is told in the introductory paragraph (Kerry shot a goose during an early-morning hunt in Boardman, Ohio). Thus the author of article creates a pun (wordplay) in the context of which both meanings of expression - direct and phraseological are maintained.

Periphrases and specifications belong to lexical-semantic TSM which aim to allocate some aspect of the manysided phenomenon (person, subject and a situation) and to concentrate attention on one its features. A periphrasis allows to replace words, focus attention on one characteristic of an object, or to hide its some sides. For example, in the following utterance the emphasis is placed on one characteristic - Afghanistan - a country liberated with the help of the USA. "It is deeply troubling that a country we helped liberate would hold a person to account because they chose a particular religion over another," Mr. Bush said, Washington Times, March 23, 2006.

The impact of lexical and pragmatic TSM is mainly based on the transfer of the author's attitude to the object.

TSM deictic units serve "to update components of a situation of the speech and components of the denotative statement" (Linguistic encyclopedic dictionary, 2002). Various forms of addressing are often used as rhetorical reception - an appeal to the audience, and as method of demagogy - especially the use of the pronoun of "solidarity" and "we" can be observed.

E.g. "It's my country," Fadhil said. "This is the place I was born, and I want to die here. I don't want to go outside. We - the students - we will change it. It's our duty", Los Angeles Times, March 25, 2006. In this statement several deictic units are interacted such as I, my, we, our, here. The leading role is assigned to the pronoun of solidarity of we, which is repeated within one sentence and characterized by a separate specification of the students. Thus, the social group of students to which belongs the subject of the statement, is presented as a whole and it attributes the general intensions.

The same is about the following example which is said in a form of message to nation from the behalf of the President of the USA, Barack Obama who uses deictic units such as we, our referring America and American story so that provoking patriotism to the image of American nation:

"America is the country that helped liberate a continent from the march of a madman. We are the country that told the brave people of a divided city that we were Berliners too. We sent generations of young people to serve as ambassadors for peace in countries all over the world. And we're the country that rushed aid throughout Asia for the victims of a devastated tsunami.

Now it's our moment to lead - our generation's time to tell another great American story. So some day we can tell our children that this was the time when we helped forge peace in the Middle East. That this was the time when we confronted climate change and secured the weapons that could destroy the human race. This was the time when we brought opportunity to those forgotten corners of the world. And this was the time when we renewed the America that 
has led generations of weary travelers from all over the world to find opportunity, and liberty, and hope on our doorstep"(Barack Obama, 2007).

Lexical TSM extensively uses possibilities of connotations, because the main function of connotations is a function of influence. Words with an evaluation connotation bring certain evaluation without their direct manifestation in the text, but are shown in the meaning.

E.g. The unfortunate ban by Gov. Robert L. Ehrlich Jr. that prevents state employees from talking to a reporter and a columnist for The Sun ..., Boston Globe, March 30, 2006. There is an evaluation component in word unfortunate: happening because of bad luck and often having serious or dangerous results (Longman Dictionary of Contemporary English, 1995).

Some lexical units can take evolution in the context. E.g. Russian authorities refused to ease their tough stance in a political dispute with Ukraine over gas prices Friday, issuing a stern new threat to halt supplies to its neighbor on New Year's Day and criticizing Kiev's call for more time reach a deal, Washington Post, January 30, 2008.

Definition of political doesn't have evaluation connotation. Political means «connected with the government or public affairs of a country and its relations with other countries» (Longman Dictionary of Contemporary English, 1995). In the context of the whole discourse, the definition gets sharply negative evaluation, and describes the condemnation of the actions of the Russian side, which uses the "energy weapon" for political purposes. This is based on negative components of meanings which are used in the following contexts: tough - likely to be violent or to contain violence, not kind or pleasant (Cambridge Advanced Learner's Dictionary, 2008); stern - severe, or showing disapproval (Cambridge Advanced Learner's Dictionary, 2008); threat - a suggestion that something unpleasant or violent will happen, especially if a particular action or order is not followed (Cambridge Advanced Learner's Dictionary, 2008).

There are always emotive components of meaning in the meaning of many lexical units. There is an appeal to emotions of the addressee by means of a choice of lexical units on emotive connotation. It should be noted that the emotiveness can be caused by the context as well. It is known that the category of emotiveness is closely connected with evaluation.

E.g. President Bush formally a second term in office Wednesday ... after a taut and chaotic contest..., USA, October 22, 2004.

Highlighted units taut and chaotic negatively characterize election as «tense» (showing signs of worry or anxiety (Longman Dictionary of Contemporary English, 1995) and «chaotic» (a chaotic situation is one in which everything is happening in a confused way (Longman Dictionary of Contemporary English, 1995).

Words with an expressional connotation promote manipulative influence of a discourse. An expression is "a property of the text or part of the text which conveys meaning with the increased intensity, expressing internal state of the speaker" (Arnold, 1975).

"These and other inflammatory images deserve our scorn, just as the violence against embassies and military installations are an unacceptable and intolerable form of protest," said Senator John F. Kerry, Democrat of Massachusetts, Boston Globe, February 16, 2006.

Here the expressiveness is put in word-formation means - in negative prefixes. Unacceptable is characterized by the reviewer as something that is unacceptable, something that is wrong or bad that you think it should not be allowed (Longman Dictionary of Contemporary English, 1995). Intolerable is too difficult, unpleasant, annoying etc for you to bear (Longman Dictionary of Contemporary English, 1995).

Words with a stylistic connotation are lexical units, the basic meaning of which is complemented by stylistic elements that characterize the condition of speech, the sphere of language activity, the social relations of participants and etc. The use of the words and expressions that belong to book or colloquial layers creates stylistic contrast and increase expressivity of the text on the background of the dominance of neutral vocabulary of the message. In addition the author can achieve a set of effects: irony, even sarcasm, introduction of the addressee to a certain environment, reducing the meaning of the phenomenon and others.

E.g. ...this week's festivities also provide an opportunity for an enormous schmooze-fest sponsored by interests.., USA, October 23, 2006.

So, informal lexis is used in this example: schmooze - «gossiping» ((AmE si.) to talk about unimportant things (Longman Dictionary of Contemporary English, 1995), fest is an oral abbreviation for festival (a special occasion when people celebrate something such as a religious event, and there is often a public holiday (Longman Dictionary of Contemporary English, 1995)). Thus, the meaning of the described events is significantly reduced - the inauguration of the president, the effect of sarcasm is reached. 
Words with an ideological connotation have a manipulative feature. "The ideological component of meaning can be characterized as reflecting certain political, ideological, social, economic representations which are the basis for identification various, sometimes conflicting points of views. These words are called as "sacred formulas" (Nikitina, 2006). The use of words in its manipulative purposes such as democracy, law, freedom of thought, national security, etc are peculiar to the American political discourse of mass media. These concepts are often used by politicians to justify their actions to the public.

For example, Muslims here tend to speak of justice. ... There is a widespread feeling that the region's governments deny their people justice. ...All they want is justice», Herald Tribune, February 12, 2006. In this case the author can achieve a positive effect of the audience, as social justice is one of values of modern society.

Euphemisms represent reality in more favorable light, often have positive emotional coloring, thereby making emotional impact as well. I.R. Galperin notices that the purpose of political euphemisms is to suppress, mislead public opinion and to express the unpleasant in a softer way" (Galperin, 1981). There is the euphemism which veiled actions in Iraq in the following statement:

E.g. McCain said he's learned much about the intelligence agencies and how they interact now and in the run-up to the Iraq operation for WMD proliferation prevention, USA, March 23, 2005.

Thus, war in Iraq is presented as "an operation to prevent distribution of weapons of mass destruction" that gives it positive coloring and often used in the American mass media.

The opposite aim is pursued by dysphemism based on underlining a certain negative feature, their purpose is "to create a perception of object as suspicious and undesirable, qualify it so that to cause hostility, disgust or hatred" (Sheygal, 2004). For example, the author uses the dysphemism when calling the program for telephone tapping, emphasizing the hostile relation to the population of the country: domestic spying watch, Washington Post, March 23, 2006, "domestic spying". This dysphemism pushes together two concepts - domestic (happening within a country and not involving any other countries (Longman Dictionary of Contemporary English, 1995)), and spying watch (to spy - to secretly collect information about an enemy country or an organization you are competing against (Longman Dictionary of Contemporary English, 1995)).

Sophistic or sophisticated lexis is difficult, unusual and isn't clear for the audience although it can have a definite meaning. This feature is the basis of its use in the manipulative purposes. Alternative mechanism of action has terms words or phrases that "designate concepts of special field of meaning or activity" (Linguistic encyclopedic dictionary, 2002). Such lexical units "possess magic impact on consciousness with a print of authority of science" (Kara-Murza, 2000). For example, the use of Latin expression in the following passage, undoubtedly, burdens it, makes it difficult to read, but makes it very authoritative: Their agreement did not turn out to he the sine qua non of the ... future, Washington Post, January 05, 2008, (sine qua non - (formal use of Latin) something that you must have, or which must exist, for something else to be possible (Longman Dictionary of Contemporary English, 1995)). Sine qua non, being an example of sophisticated lexis, that means "compulsory condition", belongs to a formal layer of lexis and isn't clear to every reader.

Barbarisms are "foreign-language words and expressions used in the speech in order to describe realias, customs and other nations" (Big Soviet Encyclopedia, 2015). These words are intended to draw attention of the reader. They are often used as a tool of irony and a parody. But their degree of manipulation mainly depends on how they are treated by the author. For example, Television news programs extolled Ukrainians to hang tough and make sacrifices, and talk shows featured Russia's most xenophobic politicians, who referred repeatedly to Ukrainians using a slur deeply offensive to many here - "khokhly" - which refers to the appearance of Ukrainian Cossacks and has come to mean "bumpkins", Washington Post, January 07, 2006.

The author of article explains the meaning of colloquial word bumpkins as someone from the countryside who is considered to be stupid (informal) (Longman Dictionary of Contemporary English, 1995) by using the method of calque which in the Russian language sounds like "khokhly". The comments on etymology and its usage are also given: it is deeply offensive and very rude or insulting and likely to upset people (Longman Dictionary of Contemporary English, 1995); slur is an unfair criticism that is intended to make people dislike someone or something (Longman Dictionary of Contemporary English, 1995). Negative emotional-evaluative coloring can be observed in such explanation. As a result, the author focuses attention of the reader on foreign-language word khokhly, and through it shows the unfair attitude to Ukraine.

3. Functioning at the grammatical level, TSM uses possibilities of morphology and syntax: a choice of a grammatical forms, elliptic language, figures of speech, features of communicative types of sentences and etc.

C. Schäffner explains that: the ideological aspect can be determined within a text itself, both at the lexical level (reflected, for example, in the deliberate choice or avoidance of a particular word) and at the grammatical level (for example, the use of passive structures to avoid an expression of agency). Ideological aspects can be more or less 
obvious in texts, depending on the topic of a text, its genre and communicative purposes (Schäffner, 2003).

As for morphological means, first of all it should be noted the use of passive voice instead of active. Its principle of influence is similar to the lexical nominalization of TSM - to leave the responsible person (figure) "behind the screen". For example:

...Arab Australians and Muslim Australians from other backgrounds began to be subjected to a highly increased level of vilification and even assault in public places, Herald Tribune, February 15, 2006. The subject of action isn't mentioned in this passage, but it is camouflaged by means of passive voice: began to be subjected, i.e. "started being exposed" but who is an agent - is unknown. The author of article doesn't designate a responsible person which is preceded by means of use of a nominalization: vilification and assault.

The choice of a grammatical form is capable to actualize the action (the Present tense instead of the Past tense), to give dynamism and emotionality (continuous forms), to express the relation to opportunity, desirability, need of a certain event (subjunctive mood).

E.g. I recall the first days after the attacks. The fear, the anger, the desire for retribution that is everywhere. And also - the love that flows freely... as people from other nations console us, Philadelphia Daily News, September 11, 2002.

Such language could be seen as provocative at a time when the United States and its European allies is bringing Iran before the U.N. Security Council to answer allegations that it is secretly developing nuclear weapons, Washington Post, March 25, 2006.

In the first example the present tense (Present Indefinite Tense) is used, although we are talking about events in the past. Such choice of a grammatical form allows to achieve the effect of empathy at the time of reading. Use of "the historical present" is intended to create a bright picture of the described events (Blokh, 2000). Continuous form in the second example indicates events which are in development (is bringing, is developing). In the framework of this statement, such choice is caused by the need to emphasize that action is dynamically developed at the time of another, not absolutely appropriate situation. "Continuation forms are more emotional" (Arnold, 1975).

Various syntactic means are one more resource of a manipulative ability of a political discourse of mass media. Elliptic and parallel constructions, and inversion and isolation as well are the most widespread means of influence. So, elliptic language (with the admission of some elements of the utterance) forces the reader to finish or complete sentences, and the reader becomes the coauthor of a discourse to some extent, so that accepts the point of view of the real author.

Parallelism is a compound of two or more sentences (or parts of them) by the strict compliance of their structure grammatical and semantic (Linguistic encyclopedic dictionary, 2002).

E.g. Corporate tax loopholes? Gone "in a nanosecond," says Kerry. The Bush administration's new overtime regulations? Reversed on Day One, says running mate John Edwards, USA, October 23, 2004.

Several instruments of speech manipulation at the grammatical level are involved in this passage. First, there are elliptic constructions: Corporate tax loopholes?, Gone "in a nanosecond", The Bush administration's new overtime regulations? Reversed on Day One, which not only create a life flow of spoken language, but also force the reader to complete phrases, as well as set a special rhythm and tempo of the utterance. Secondly, constructions: Gone "in a nanosecond," says Kerry, Reversed on Day One, says running mate John Edwards, and also elliptic questions are mentioned above. It is known that "ellipsis... gives to the text dynamism, a big expressiveness and strengthens its expressivity" (Linguistic encyclopedic dictionary, 2002). The same can be said about parallel constructions which besides focus attention of the reader on certain elements of the utterance.

Inversion carries out emphatic function as TSM at the grammatical level. E.g. Ahead the Iranians move. And the situation is changing daily, Los Angeles Times, March 29, 2006. An unusual word order allows to select that part of the sentence which the author considers as the most important or informative. The adverb ahead is presented in an initial position although it usually follows after a verb (to move ahead), thereby the emphasis is placed on progressiveness and dynamism of the movement.

Choice of communicative type of the sentence is one more way to affect on perception of the reader. Questions (besides narrative ones which are considered as norm in transferring information) are the most popular for the purpose of manipulation in mass media among four communicative types of sentences (narrative, interrogative, exclamatory, incentive). There are various types of questions in analytical and editorial materials, in particular rhetorical ones which don't assume the answer, and act as the hidden statement. The interrogative form is convenient for "hinting" utterances: It is a strange irony: John McCain as the last Bush Republican? Washington Post, March 28, 2008. In this case the sentence John McCain as the last Bush Republican? isn't an interrogative sentence in the usual sense, it has only a formal sign - a question mark. Its purpose is to express a sneer.

Thus, speech manipulation at the grammatical level uses both possibilities of morphological categories and forms, 
and syntactic constructions and categories. In the first case TSM transfers various visions of a situation by the author: responsibility of subjects for commission of actions, relationships of cause and effect between events, importance of one action against another and etc. TSM of the second group which are syntactic constructions and use of unusual communicative types of the sentences carry out the general task. These expressive syntactic means are designed to intensify the utterance.

\section{Conclusion}

The investigated examples perfectly demonstrate how manipulation became high-frequency phenomena which have a huge impact on the consciousness in the political struggle. Because the subject of a political discourse of mass media which reflects some interests and has some purposes and tasks, interprets reality in the text. The main aim of political discourse is struggle for power. Concerning this Jan Blommaert claims that "power is not a bad thing - those who are in power will confirm it. They will argue convincingly that power is necessary in every system, for it is often that which allows the system to function in particular ways, without which the system would disintegrate or cease to operate effectively. Yet, power is a concern to many people, something that is easily translated into topics of discussion or narration. Power, its actors, its victims, and its mechanisms are often the talk of the town, and our everyday conversations, our mass media, our creative arts gladly use power as themes or motifs in discourses on society at large... Thus, we seem to have a strangely ambivalent attitude towards power: it attracts as well as repels; it fascinates and abhors at the same time; it has a beauty as well as an ugliness to it that match those of few other phenomena (Blommaert, 2005)".

So, tools of speech manipulation of a political discourse of mass media are present at all levels of language phonographic, lexical and grammatical. The widest layer of speech means of manipulation is presented at the lexical level. TSM of different levels interacts with each other, which allows to achieve much more effective impact on the reader.

Speech manipulation within a political discourse of mass media is a multidimensional phenomenon. Achievement of one of the main tasks of a political discourse of mass media, i.e. management of public opinion can allow such features as focus and dedication on the mass addressee, and invisibility as well. Speech manipulation doesn't open its viewpoints about influence, and its efficiency depends on that. Studying of the mechanism of a manipulation by linguistic means helps to avoid psycho-technical effect of speech manipulation, or speech demagogy, speech aggression or even speech violence.

\section{References}

Arnold, I.V. (1975). Interpretation of the art text: types of promotion and problem of expressivity, Expressional means of English. Leningrad.

Barack Obama addresses the Chicago Council on Global Affairs. (April 23, 2007). Retrieved from February 8, 2015, from https://my.barackobama.com/page/content/fpccgal

Big Soviet Encyclopedia (February 8, 2015). Retrieved from February 8, 2015, from http://www.rubricon.com/bse_1.asp

Blakar, P.M. (1987). Language as tool of the social power, Language and modeling of social influence. Moscow.

Blommaert, J. (2005). Discourse: key topics in sociolinguistics. New York, NY: Cambridge University Press.

Blokh, M.Y. (2000). A course in theoretical English grammar (3rd edition). Moscow: Vysshaya shkola.

Cambridge Advanced Learner's Dictionary (2008). Cambridge University press

Dickson, P.(2013). Words from the White House. New York.

Dijk Teun A. Van (2006). Discourse and Manipulation. Discourse \& Society 17, no. 2: 359-383. SAGE Publications London, Thousand Oaks,CA and New Delhi http://www.discourses.org/OldArticles/Discourse and manipulation.pdf.

Galperin, I.R. (1981). Stylistics. Moscow

Issers, O.S. (1996). What are politicians speak to the people to be pleasant. Bulletin of Omsk university (pp.71-74). \# 1.

Kara-Murza, S.G. (2003). Short course of manipulation on consciousness. Moscow.

Kara-Murza, S.G. (2000). Manipulation with consciousness. Moscow.

Linguistic encyclopedic dictionary (2002). Moscow.

Longman Dictionary of Contemporary English (1995). Longman Group Ltd.

Nikitina, K.V. (2006). Technologies of speech manipulation in a political discourse of mass media (on material of newspapers of the USA) (abstract of a thesis of cand. Phil. sciences). Ufa.

Sheygal, E.I. (2004). Semiotics of a political discourse. Moscow.

Schäffner , C. (2003). Third ways and new centers: Ideological unity or difference? In M. Calzada-Perez (Ed.), Apropos of ideology (pp. 23-42). Manchester: St. Irome.

Troshina, N. N. (1990). Stylistic parameters of texts of mass communication and realization of communicative strategy of the subject of speech influence, Speech influence in the sphere of mass communication. Moscow.

Veretenkina, L.Yu. (1999). Linguistic expression of interpersonal manipulations (to statement of a problem), The international scientific 
ISSN 2039-2117 (online)

ISSN 2039-9340 (print)
Mediterranean Journal of Social Sciences MCSER Publishing, Rome-Italy
Vol 6 No 4 S1 July 2015

conference devoted to memory of professor V. S. Yurchenko. Saratov. Vlasov, Yu.M. (1976). Promotion behind a facade of news. Moscow. 